\title{
Prediction of fog/visibility over India using NWP Model
}

\author{
Aditi Singh*, John P George and Gopal Raman Iyengar \\ National Centre for Medium Range Weather Forecasting, Earth System Science Organization, Ministry of Earth \\ Sciences, Noida 201 309, India. \\ *Corresponding author. e-mail: aditi@ncmrwf.gov.in
}

MS received 11 November 2016; revised 21 July 2017; accepted 22 July 2017; published online 6 March 2018

Frequent occurrence of fog in different parts of northern India is common during the winter months of December and January. Low visibility conditions due to fog disrupt normal public life. Visibility conditions heavily affect both surface and air transport. A number of flights are either diverted or cancelled every year during the winter season due to low visibility conditions, experienced at different airports of north India. Thus, fog and visibility forecasts over plains of north India become very important during winter months. This study aims to understand the ability of a NWP model (NCMRWF, Unified Model, NCUM) with a diagnostic visibility scheme to forecast visibility over plains of north India. The present study verifies visibility forecasts obtained from NCUM against the INSAT-3D fog images and visibility observations from the METAR reports of different stations in the plains of north India. The study shows that the visibility forecast obtained from NCUM can provide reasonably good indication of the spatial extent of fog in advance of one day. The fog intensity is also predicted fairly well. The study also verifies the simple diagnostic model for fog which is driven by NWP model forecast of surface relative humidity and wind speed. The performance of NWP model forecast of visibility is found comparable to that from simple fog model driven by NWP forecast of relative humidity and wind speed.

Keywords. Visibility; fog; Insat-3D; METARS; NCUM; north India.

\section{Introduction}

Fog and associated low visibility conditions over any region cause significant impacts on the human activities and adversely affects the economy (Gultepe et al. 2007). Thus, it is required to have an accurate prediction of fog and visibility over any area. The prediction of fog has long been a challenge and success with numerical models is also very limited mainly due to complex processes involved in the fog formation. However, continuous efforts have been made in improving models for accurate prediction of fog and visibility. Many researchers (Zdunkowski and Nielsen 1969;
Brown and Roach 1976; Brown 1980; Bergot and Guedalia 1994; Duynkerke 1999) have used the one-dimensional (1-D) models for fog prediction. A number of 1-D models such as COBEL (Bergot and Guedalia 1994), SSFM (Clark and Hopwood 2001), and Air Mass Transformation Model of Holtslag et al. (1990) have achieved some success in forecasting fog. However, the utility of these models is limited in practice as they do not incorporate the large scale meteorological conditions that affect the genesis, evolution and dissipation of fog. Thus, a three-dimensional (3-D) model, which incorporates processes like horizontal pressure gradient, advection and diffusion, is 
required for predicting fog. Mesoscale models such as Fifth-Generation NCAR/Penn State Mesoscale Model (MM5) and Weather Research Forecasting (WRF) were developed and used to forecast fog, especially the low visibility in fog by different researchers (Ballard et al. 1991; Rao and Sullivan 2003; Pagowski et al. 2004; Fu et al. 2006; Van der Velde et al. 2010). These models use parameterization schemes to forecast fog visibility as they do not have detailed microphysical processes. The liquid water content (LWC)/ice water content (IWC), temperature or relative humidity is often used to parameterize visibility in these models (Bang et al. 2008). However, the study of fog/visibility prediction using the numerical models over India is very limited (Gupta 1987; Mohapatra and Thulsidas 1998; Roybhowmik et al. 2004; Goswami and Tyagi 2007).

Fog formation over different parts of northern India is a common phenomenon in winter season every year. Most of the places observe dense fog during peak winter months of December and January. The analysis of fog occurrence over Delhi, for 4 months (November-February) during 2002-2011, shows the highest frequency in January $(\sim 79 \%)$ and December ( 78\%; Swagat and Mohan 2014). The Indira Gandhi International Airport (IGIA), New Delhi, experienced highest number of fog hours during the months of December and January 2008-2009, which disrupted the aviation services severely (Jenamani and Tyagi 2011).

Thus, an attempt has been made in the present study to understand the accuracy of fog/visibility forecast by a numerical weather forecast model over different places lying in northern India. The United Kingdom Meteorological Office (UKMO), Unified Model (UM) (MetUM) data assimilation system, which is being run at NCMRWF (known as NCUM) since 2012 (Rajagopal et al. 2012), is used for predicting the visibility.

The skill of NCUM visibility forecast is critically dependent on visibility parameterization scheme. Forecast of visibility depends on the relative humidity and the aerosol content, which is kept constant in NCUM and is one of the limitations of the model. Thus, a diagnostic method based on the values of surface relative humidity and wind speed is also used to detect fog. Zhou and Du (2010) utilized liquid water content (LWC), cloud base/top rule and surface relative humidity wind speed rule to detect fog. However, rule based on surface relative humidity and wind speed is utilized in present study to detect fog as the cloud base/top rule is good for large scale events like marine and coastal fog and not for shallow or ground fog which builds upward from the ground and may lie below the lowest model level (Zhou et al. 2007).

The study is divided into different sections. Next section gives the details of the model and visibility parameterization scheme used to forecast visibility. Section 3 gives the methodology and the data used in the present study. The performance of NCUM in predicting the surface meteorological variables is analyzed in section 4 and conclusions of the study are discussed in section 5 .

\section{Model description}

\subsection{NCMRWF Unified Model (NCUM)}

The main components of UKMO global forecast suite at NCMRWF (NCUM) are (i) observation preprocessing (OPS), (ii) four dimensional variation (4D-Var) and (iii) Unified Model (UM). OPS is used to prepare quality controlled observations, which are utilized by $4 \mathrm{D}$-Var system to produce the analysis. This analysis is the best estimate of the atmospheric state and is used as initial condition for the UM forecast. Six hourly data centered at 00, 06, 12 and 18 UTC is processed and packed using OPS for the four data assimilation cycles $(00,06$, 12 and 18 UTC cycles). The analysis is prepared for all the cycles using the 4D-Var data assimilation. A deterministic 10-day forecast is generated everyday based on 00 UTC analysis.

All the components of NCUM are similar to UKMO except the data preprocessing package Met office (MetDB). Another data pre-processing system is developed at NCMRWF, which prepares observation data input to the OPS in 'obstore' or 'bufr' format using the observations received at NCMRWF through GTS and various satellite providers including NOAA-NESDIS and MOSDAC (ISRO; Prasad 2012; Prasad and Indira Rani 2014). The obstore data created at NCMRWF is used to run NCUM since 2012. It includes different types of obstore such as surface, upper air (Sonde), aircraft, satwind, scatwinds, satellite radiances and GPS radio occulation. The obstore data created at NCMRWF is monitored using in-house monitoring packages and is compared with those received from UKMO. Regular comparison of both types of obstore revealed that even though the quantity of data received at NCMRWF is comparatively less for some type of observations, there is a good global coverage in the NCMRWF obstores. 
The horizontal resolution of the NCUM is approximately $17 \mathrm{~km}$ and it has 70 vertical levels. The first level of model is at $20 \mathrm{~m}$ above surface and the model top is at $80 \mathrm{~km}$. The dynamical core of the model uses semi-implicit, semi-Lagrangian formulation to solve the non-hydrostatic, fully compressible deep atmosphere equations of motion discretized on a regular latitude/longitude grid (Davies et al. 2005). The radiation scheme is the two-stream radiation code of Edwards and Slingo (1996) with nine bands in long wave and six bands in short wave region. The atmospheric boundary layer is parameterized with turbulence closure scheme of Lock et al. (2000), which is further modified as described in Lock (2001) and Brown et al. (2008). The land surface and its interactions with the atmosphere are modeled using JULES (Joint UK Land Environment Simulator) surface model (Best et al. 2011; Clark et al. 2011). A mass flux scheme based on Gregory and Rowntree (1990) is used to represent convection and convective momentum transport. Large scale precipitation is represented using Wilson and Ballard (1999) and clouds are modeled using prognostic cloud fraction and prognostic condensate (PC2) scheme (Wilson et al. 2008a, b).

\subsection{Diagnosis of surface visibility in NCUM}

Visibility forecasting is a complex issue and it is difficult to capture all of its characteristics by any model. Visibility is one of the forecast products of NCUM. There are some other operational models elsewhere globally which also predict visibility. The HIRLAM model at Danish Meteorological Institute (DMI; Petersen and Nielsen 2000) is one of such model which predicts visibility at $2 \mathrm{~m}$ height using the variables such as relative humidity, temperature and cloud cover. The Rapid Update Cycle (RUC) model of USA, calculates visibility from prognostic relative humidity, cloud and hydrometeor fields (Smirnova et al. 2000). However, visibility of any region also depends on the aerosol content of that region. In HIRLAM-DMI constant aerosol concentration is assumed, whereas the RUC model neglects aerosol. The rapid refresh (RAP) model replaced the RUC model of USA in 2012 and aerosols were included in RAP.

Visibility in NCUM is calculated from the variables such as specific humidity $(q)$, liquid water content $\left(q_{L}\right)$ using droplet growth equations and assuming standard values for aerosol concentration, density and dry radius. The equation used to compute visibility in NCUM is given in terms of fog droplet radius $(r)$ and number density $(N)$ using the equation given by Clark et al. (2008)

$$
\mathrm{Vis}=\frac{-\ln \epsilon}{\beta_{\text {air }}+N r^{2} 1.5 \pi}
$$

where $\beta_{\text {air }}$ is the extinction coefficient of clean air taken as constant and $N r^{2} 1.5 \pi=\beta(R H)$ is the extinction coefficient due to aerosol particles, which become fog droplets either activated or inactivated.

Thus, visibility in NCUM depends on whether the fog droplets are activated or not. Inactivated droplets are the aerosol particles with small amount of liquid water and the droplet radius is dependent on relative humidity in terms of the equilibrium equation (Pruppacher and Klett 1978)

$$
R H=\exp \left(\frac{A}{r}-\frac{B}{\left(\frac{r}{r_{d}}\right)^{3}-1}\right)
$$

where $B$ is the activation parameter $(=0.14), A$ is constant related to surface tension of water $(1.2 \times$ $\left.10^{-9}\right)$ and $r_{d}$ is dry radius computed as follows:

$$
r_{d}=r_{0}\left(\frac{m}{m_{0}}\right)^{1 / 6}
$$

where $m$ is the aerosol mass mixing ratio (a fixed value of $m$ is used in NCUM), $m_{0}$ is constant known as standard aerosol mass mixing ratio and $r_{0}$ is the radius of standard aerosol particle.

When no activated particles are present, the droplet radius is computed from equation (2) by ignoring the term involving $A$ and is given by

$$
r=r_{d}\left(1-\frac{B}{\ln (R H)}\right)^{1 / 3} .
$$

The radius at which dry aerosol particles become active fog droplets is known as activation radius. The activation radius $\left(r_{\text {act }}\right)$ is computed from equation (2), assuming that close to activation, $r$ becomes much greater than $r_{d}$ and thus

$$
r_{\mathrm{act}}=\sqrt{\frac{3 B r_{d}^{3}}{A}} .
$$

Activated fog droplets grow rapidly and the cloud water content $\left(q_{L}\right)$ is related to the droplet radius 
by the equation

$$
q_{L}=\frac{4}{3} \pi\left(r^{3}-r_{d}^{3}\right) \rho_{w} N
$$

Thus, radius of inactivated fog droplets is computed using equation (4) and the radius of activated fog droplets is obtained from equation (6). The specification of droplet radius changes from equations (4-6) at the point of activation. The two equations used to compute the droplet radius are combined in one single equation as:

$$
q_{t}=R H(r) q_{s}(T)+q_{L}(r)
$$

where $R H(r)$ and $q L(r)$ are obtained from equations (2 and 6), respectively, $q_{s}(T)$ is the saturation specific humidity at temperature $T$. Equation (7) is solved iteratively with Newton Raphson method using the droplet growth equation (2) and the relationship between liquid water and droplet radius given in equation (6).

The computation of radius of fog droplet is dependent on relative humidity because the activation of fog droplets depends on the relative humidity and thus the extinction coefficient $\beta(R H)$ is dependent on relative humidity. The number density of aerosol is assumed to be equivalent to fog droplets for use in equations ( 1 and 7 ), assuming that all fog droplets are activated in later case.

The operational version of UKMO, Unified Model (UM) uses the prognostic aerosol content $(m)$ to predict visibility using the parameterization scheme discussed above. However, fixed value of aerosol content is used in NCUM. The value of aerosol content is fixed according to cleaner conditions over a site in UK. This is one of the limitations of NCUM.

The degradation of visibility in model occurs only when aerosol become fog droplets by absorbing water. For a given relative humidity, the aerosol content fixed according to cleaner conditions in the model gives higher values of visibility as compared to the polluted conditions, prevalent over northern plains of India. Analysis of long-term measurements by Central pollution Control Board (CPCB) India has revealed very high annual average concentrations $\left(>150 \mu \mathrm{g} \mathrm{m}^{-3}\right.$, which is the critical range according to air quality standard in India) of particulate matter $\left(\mathrm{PM}_{10}\right)$ in the atmosphere of major cities in the northern plains of India (http://www.cpcb.nic.in). The more number of aerosol particles results in the formation of more fog droplets and causes degradation of visibility. Sensitivity studies carried out using higher values of aerosol content ( $\sim 10$ times of the values used in NCUM) reduce the visibility significantly. As the value of aerosol content is not changed in the model, the visibility values are normalized and used in the present study.

\section{Evaluation method and data}

An evaluation of visibility/fog prediction from NCUM over northern India is carried out during the months of December and January. This is because most of the places in this region experiences high occurrence of fog during these two months. Spatial extent of fog over any area is identified using the satellite observations. Ground based and conventional observational networks use horizontal visibility (Vis) to identify fog. If observed visibility at a particular location is $\leq 1 \mathrm{~km}$, then it is considered as foggy (WMO manual 2003). However, monitoring the spatial and temporal extent of fog over large areas becomes difficult with ground-based observations alone. Thus, satellite-based techniques are widely used to detect the real-time fog.

In the present study, both satellite imagery and ground-based observations of visibility are used to identify places affected by fog. METAR (Meteorological Aviation Reports) visibility reports and INSAT-3D satellite imagery for 28th December, 2014 is depicted in figure 1(a, b). Fog image at 0000 UTC from INSAT-3D satellite clearly shows the presence of fog at most of the places in the northern India on 28th December, 2014 (figure 1a). METAR data report at 0000 UTC showed very dense fog with very low visibility, ranging from 0 to $50 \mathrm{~m}$, at Delhi, Lucknow and Varanasi and moderate fog (visibility range 200-500 m) at Amritsar (figure 1b). The criteria for classification of fog in different categories based on observed visibility are given in table 1 . The categories are based on International Civil Aviation Organization (ICAO) definition. Day-1 forecast of visibility from NCUM based on 00 UTC 27th December, 2014 initial conditions valid for 28th December, 2014 is shown in figure $1(\mathrm{c})$. Low visibility, in range of $0-50 \mathrm{~m}$, is predicted at most of the stations including Amritsar, Delhi, Lucknow and Varanasi which matches well with observations. Thus, the forecast by NCUM is able to capture the drop in visibility during a dense fog episode in north India one day in advance. 


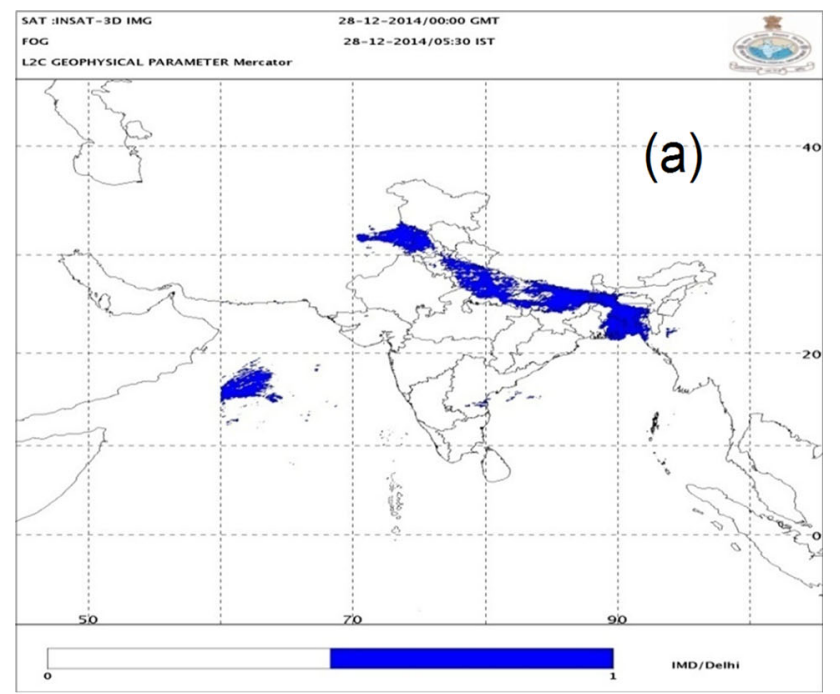

OBSERVED VISIBLITY(METAR) OOUTC 28122014

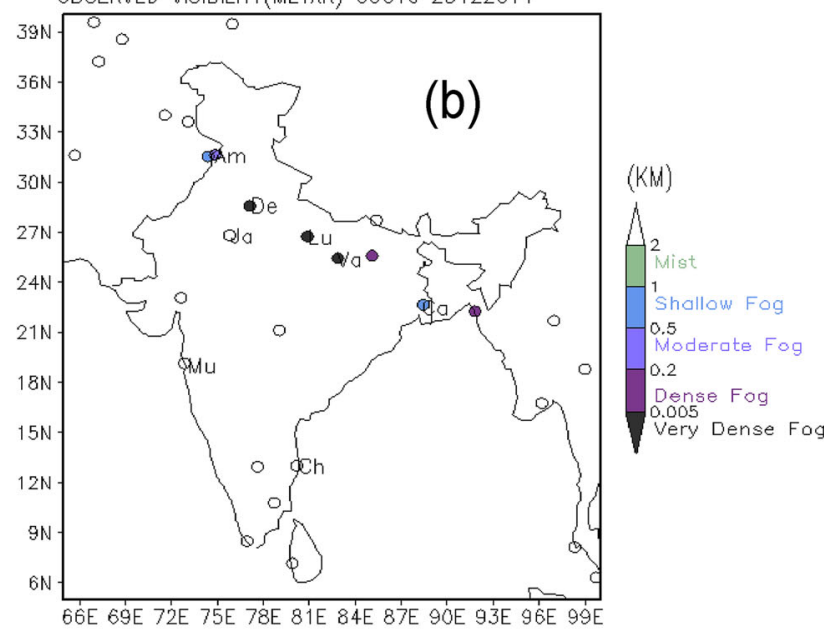

Verification Plot for 28122014

Vis(km) 24hr.Fcst VT:OOUTC28122014 IC:OOUTC27122014

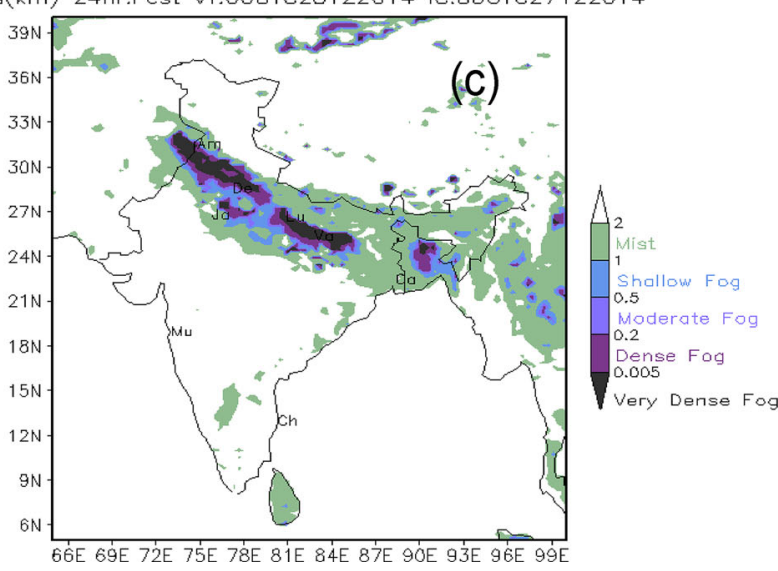

Figure 1. Observed fog from (a) INSAT-3D, (b) visibility from METARS and (c) day-1 forecast of visibility from NCUM on 28th December, 2014.

To analyze the performance of NCUM in predicting fog at various locations, visibility observations at Amritsar, Delhi, Lucknow and Varanasi from METARS are compared with Day-1 forecast
Table 1. Types of fog associated with general visibility range.

\begin{tabular}{lc}
\hline Fog types & $\begin{array}{c}\text { General visibility } \\
\text { range }(\mathrm{m})\end{array}$ \\
\hline Shallow fog & $1000-500$ \\
Moderate fog & $500-300$ \\
& $350-200$ \\
Dense fog & $200-50$ \\
Very dense fog & $<50$ \\
\hline
\end{tabular}

of visibility from NCUM during December 2014-January 2015 (figure 2). The trend in the observed visibility values is well predicted at Amritsar although the over-prediction is seen in majority of days. Model predicted visibility of less than $200 \mathrm{~m}$, indicating dense fog, which matches well with observations in few days (figure 2a). Large differences between the predicted and observed values of visibility are seen over Delhi (figure 2b) and Lucknow (figure 2c) for some days. Predicted values of visibility are found closer to the observations at Varanasi (figure 2d). Dense fog conditions with visibility $<200 \mathrm{~m}$ are predicted one day in advance at all the stations in many days.

The performance of NCUM in predicting visibility over point locations is further analyzed by computing the different skill scores such as hit rate $(\mathrm{H})$, false alarm ratio $(\mathrm{F})$, bias $(\mathrm{B})$ and equitable threat score (ETS). These scores are computed using the statistical classifications based on the threshold of visibility. As mentioned earlier, fog at any locations is defined if visibility $\leq 1 \mathrm{~km}$ at that location. If at a given location both the observed and predicted visibility is $\leq 1 \mathrm{~km}$ then it is assigned as 'hit'. If the predicted visibility $\leq 1$ $\mathrm{km}$ but observed visibility $>1 \mathrm{~km}$, it is assigned as 'false alarm'. If predicted visibility $>1 \mathrm{~km}$ and observed visibility $\leq 1 \mathrm{~km}$, it is assigned as 'miss'. If both observed and predicted visibility are $>1 \mathrm{~km}$ it is assigned as 'correct negative'.

The following performance indicators are prepared using these scores

Hit Rate $(\mathbf{H})=$ Hit/(Hit+Miss), which represents the proportion of forecasted events within whole set of observed events. It gives the ratio of number of hits divided by the total number of events observed and ranges from 0 to 1 . The perfect score is 1 .

False Alarm Rate $(\mathbf{F})=$ False Alarm $/($ False Alarm + Correct Negatives) gives the ratio of the events that are not observed but are incorrectly forecasted. It ranges from 0 to 1 and perfect score 

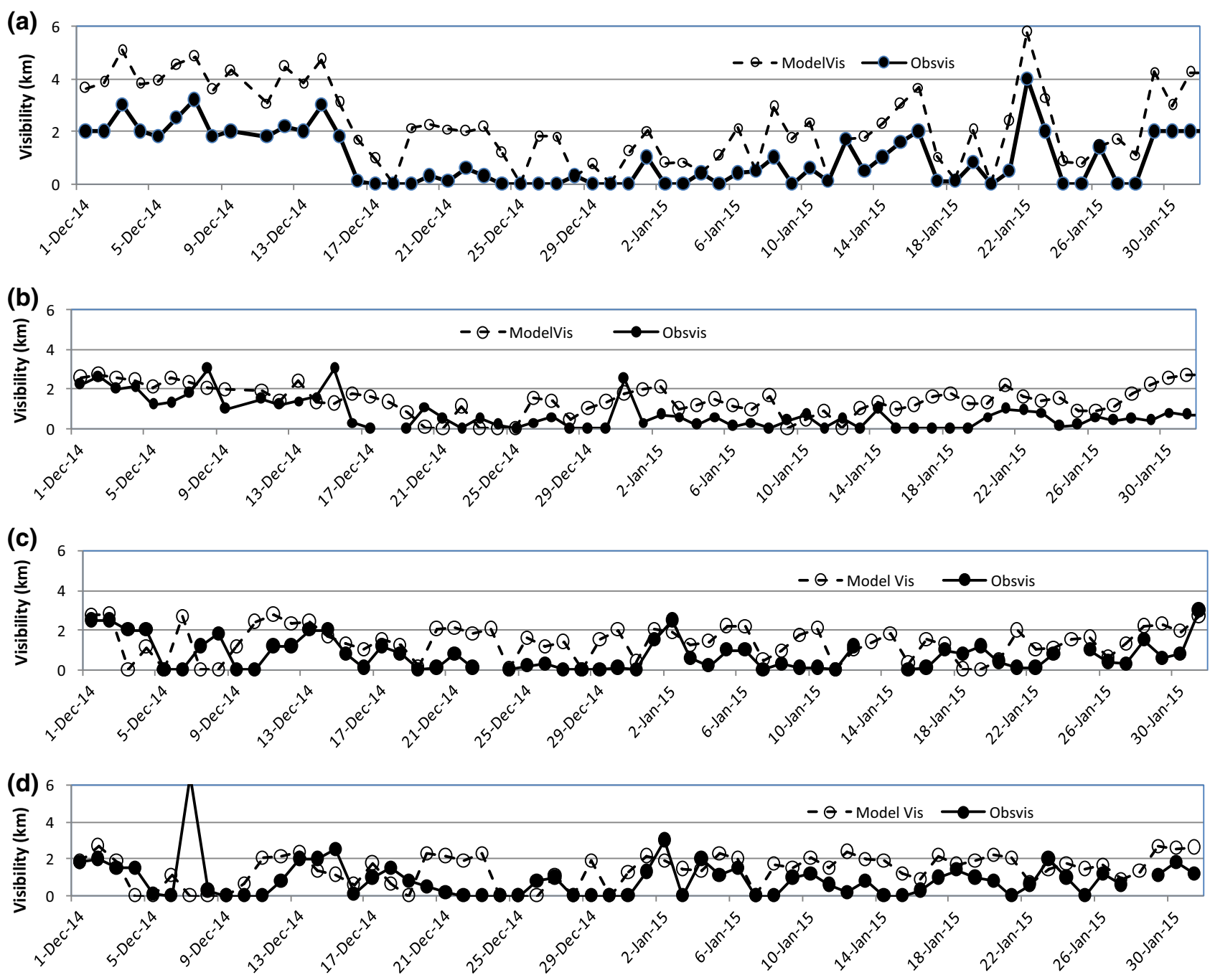

Figure 2. Comparison of day-1 forecast of visibility from NCUM with observations at (a) Amritsar, (b) Delhi, (c) Lucknow, and (d) Varanasi during December 2014-January 2015.

is zero. It is sensitive to false alarms and correct negatives. Higher values indicate either higher number of false alarm or less number of correct negatives.

Forecast Bias $(\mathbf{B})=($ Hit + False Alarm $) /($ Hit + Miss) represents the ratio of number of forecasted events to the observed events. Perfect score is 1 .

Equitable Threat Score $($ ETS $)=$ Hit-N $/($ Hit + False Alarm + Miss-N)

Where $\mathrm{N}=($ Hit + False Alarm $)($ Hit + Miss $) /($ Hit + False Alarm + Miss + Correct Negative)

Positive values of ETS indicate that model has skill, while negative values indicate unskilled models (Zhou and Du 2010).

The scores for threshold of visibility $<1 \mathrm{~km}$ obtained at four stations during December 2014 and January 2015 are given in table 2. Highest hit
Table 2. Statistical scores for visibility with threshold of 1 km at four stations for December 2014 and January 2015.

\begin{tabular}{lcccc}
\hline Station & H $(\%)$ & F (\%) & B & ETS \\
\hline Amritsar & 48.0 & 12.0 & 0.59 & 0.21 \\
Delhi & 36.0 & 00.0 & 0.36 & 0.12 \\
Lucknow & 29.0 & 29.0 & 0.41 & -0.0003 \\
Varanasi & 40.0 & 14.0 & 0.48 & 0.06 \\
\hline
\end{tabular}

rate of $50 \%$ is found over Amritsar and Varanasi. Low values of false alarm rate, $<35 \%$, are seen at all the four stations indicating less number of false alarms and more number of correct negatives. Bias values less than 1.0 (where bias $\sim 1$ means no bias) are obtained at all the stations. Low ETS values at all the stations indicate the poor performance of model. Lowest value of ETS $(=0)$ is obtained over Lucknow whereas the highest value $(\mathrm{ETS}=0.31)$ is obtained over Amritsar. These scores indicate 
that model performed well over Amritsar, Delhi and Varanasi, whereas over Lucknow model missed most of the fog events.

The reason for the higher values of visibility forecast from NCUM as compared to the observations lies in the parameterization scheme of visibility used in the model. The predicted value of visibility at any location depends on two factors predicted relative humidity and the aerosol content. A fixed value of aerosol content is used for all the locations. At a given relative humidity this limits the formation of number of fog droplets causing reduction in visibility. However, in the real atmosphere the aerosol content is different at different locations and thus for a given value of relative humidity the number of fog droplets may be higher at one place as compared to the other location thereby affecting the visibility. Thus, accurate prediction of relative humidity is another factor affecting the predicted visibility. Next section describes the performance of
NCUM in predicting relative humidity at different locations. A simple fog forecast method based on threshold of certain meteorological variables is also discussed.

\section{Prediction of fog using surface meteorological variables}

High amount of surface relative humidity and light winds are the two favorable conditions for fog formation. A simple fog forecast method based on the threshold values of surface relative humidity and wind speed is also discussed in the present study.

\subsection{Predicted relative humidity and wind speed from NCUM}

First, the performance of NCUM is analyzed for predicting surface relative humidity and wind speed. Figures 3 and 4 show the observed and
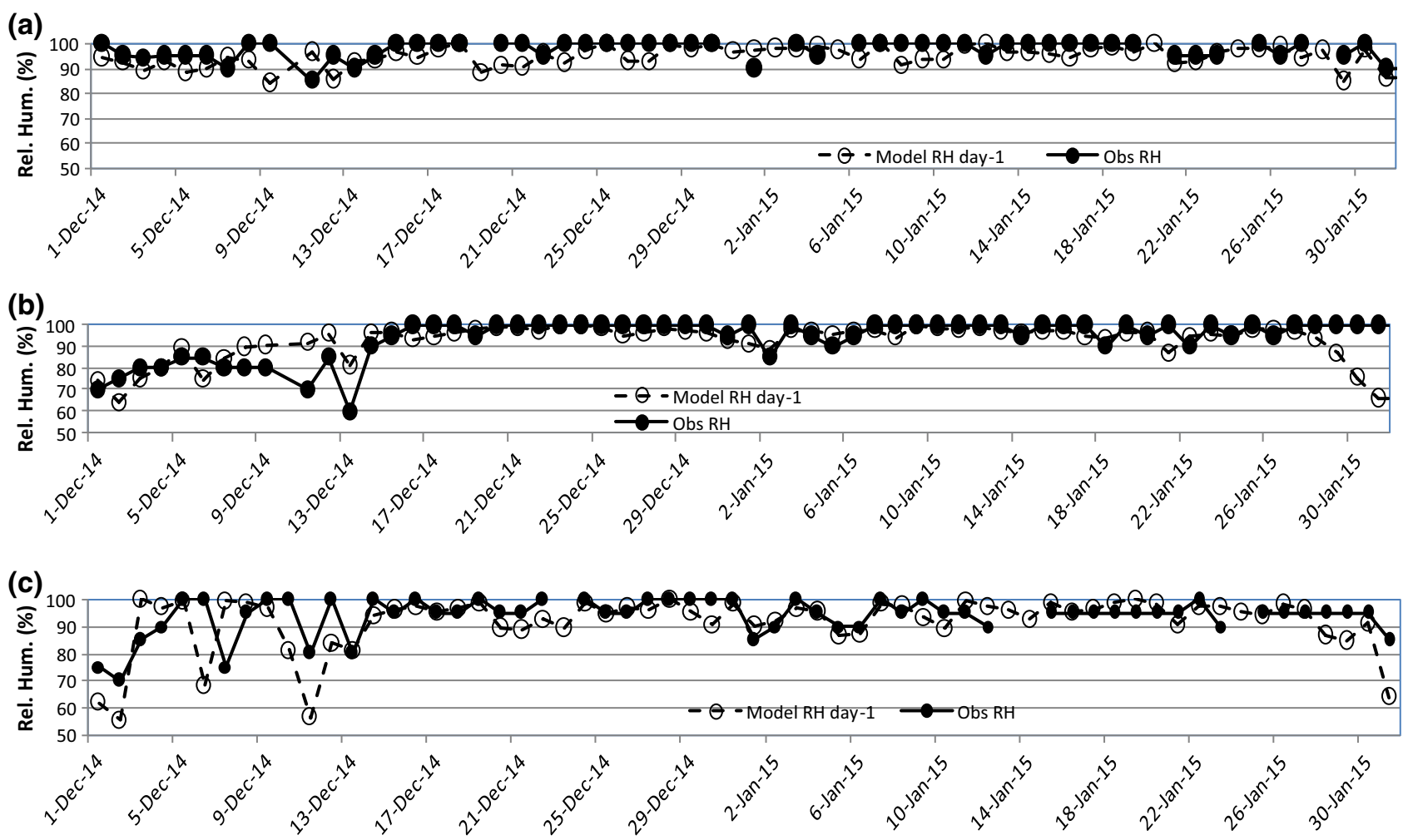

(d)

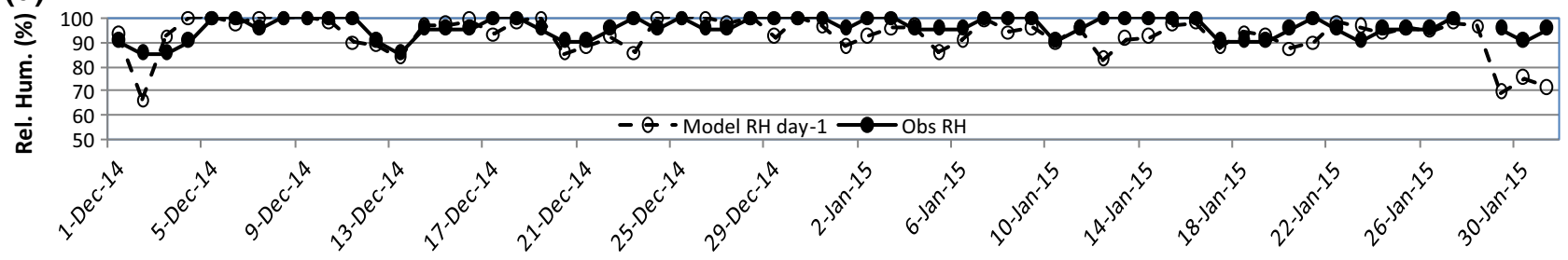

Figure 3. Comparison of day-1 forecast of relative humidity from NCUM with observations at (a) Amritsar, (b) Delhi, (c) Lucknow, and (d) Varanasi during December 2014-January 2015. 
(a)

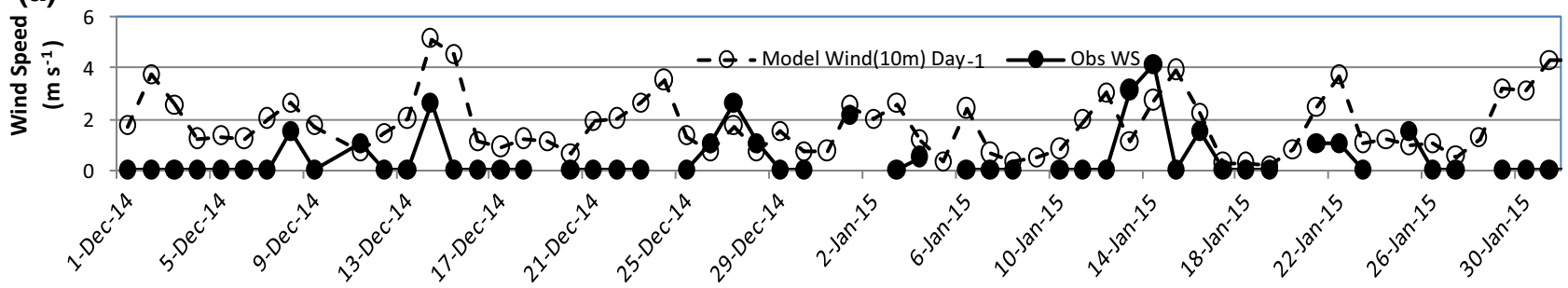

(b)

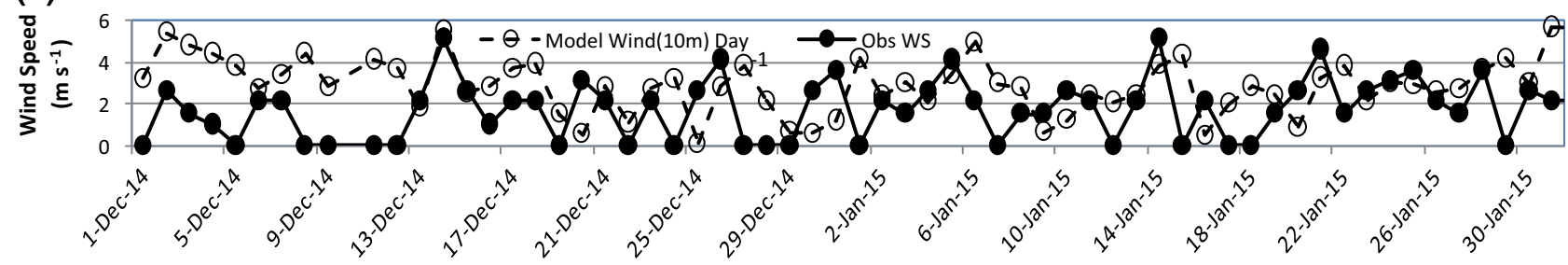

(c)

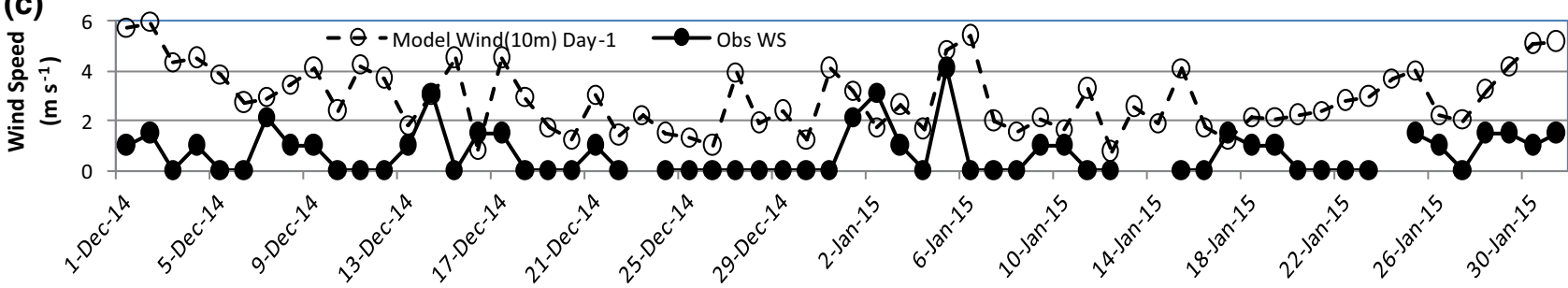

(d)

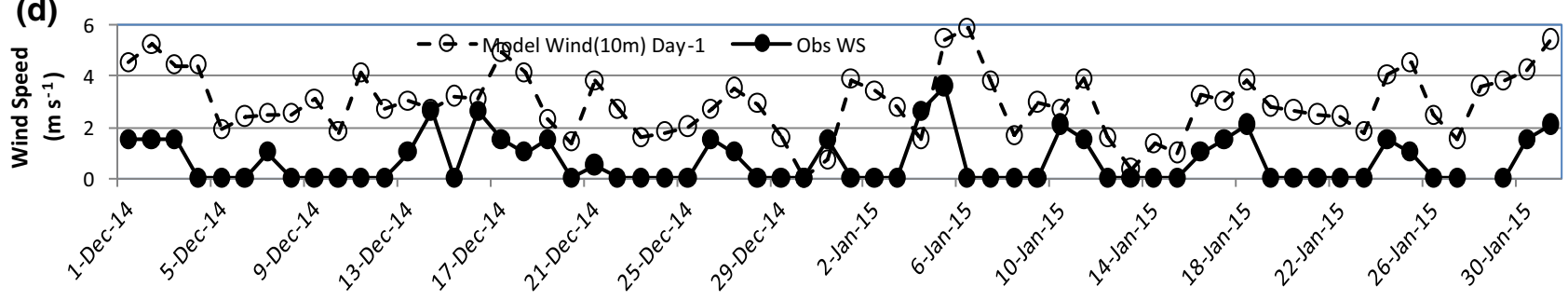

Figure 4. Comparison of day-1 forecast of wind speed from NCUM with observations at (a) Amritsar, (b) Delhi, (c) Lucknow and (d) Varanasi during December 2014-January 2015.

model predicted values of $2 \mathrm{~m}$ relative humidity and $10 \mathrm{~m}$ wind speed at the four selected stations during December 2014-Janaury 2015. A good agreement is found between the observed and predicted values of relative humidity at all the four stations. NCUM is able to predict the high values of relative humidity $(>90 \%)$ for most of the days except few at all the stations (figure 3). Both predicted and observed values of relative humidity are found $>90 \%$ for majority of days over Amritsar (figure 3a) and Varanasi (figure 3d). However, over Delhi (figure 3b) and Lucknow (figure 3c) values of relative humidity $<90 \%$ are also found in both observations and model predictions for few days. NCUM is able to predict the trend in wind speed values with some amount of over-prediction at all the stations (figure 4 ). Wind speed $<2 \mathrm{~m} \mathrm{~s}^{-1}$ is predicted by NCUM for few days which matches well with observations at all the stations. The best agreement is found over Amritsar (figure 4a).
Table 3. Statistical scores for relative humidity with threshold of $90 \%$ at four stations for December 2014 and January 2015.

\begin{tabular}{lcccc}
\hline Station & H $(\%)$ & F $(\%)$ & B & ETS \\
\hline Amritsar & 88.0 & 100.0 & 0.90 & 0.00 \\
Delhi & 90.0 & 23.0 & 0.95 & 0.11 \\
Lucknow & 57.0 & 31.0 & 0.66 & 0.04 \\
Varanasi & 65.0 & 40.0 & 0.73 & 0.03 \\
\hline
\end{tabular}

Table 3 gives the different scores computed for relative humidity with threshold of $90 \%$. For relative humidity, highest hit rate of $90 \%$ and lowest false alarm rate of $23 \%$ are found over Delhi. Further, the value of bias is close to 1.0 and ETS score is highest. Thus, the relative humidity is best predicted over Delhi. Although hit rate is found higher over Amritsar, due to zero number of correct negatives the false alarm rate becomes $100 \%$, which 
gives very poor ETS score. Lowest hit rate $(\sim 60 \%)$ is obtained over Lucknow.

The highest hit rate for visibility prediction is found over Amritsar, whereas the highest hit rate for predicting relative humidity is found over Delhi. This indicates that prediction of visibility from the model is dependent on both relative humidity and aerosol content.

A detailed analysis carried out by Dey and Girolama (2010) using 9-yr (2000-2008) seasonal climatology of shape and size segregated aerosol optical depth (AOD) with Multiangle Imaging Spectroradiometer (MISR) over Indian subcontinent, suggests higher values of AODs $(>0.4)$ over the eastern parts of the Indo-Gangetic (IG) plains as compared to the western parts during the winter season when aerosols are transported from west to east due to prevailing northwesterly winds.

As the number of aerosols and hence the number of fog droplets increases from west to east over these plains. The number of aerosols over Amritsar

Table 4. Statistical scores for wind speed with threshold of $2 \mathrm{~m} \mathrm{~s}^{-1}$ at four stations for December 2014 and January 2015.

\begin{tabular}{lcccc}
\hline Station & H $(\%)$ & F $(\%)$ & B & ETS \\
\hline Amritsar & 56.0 & 33.0 & 0.58 & 0.01 \\
Delhi & 25.0 & 23.0 & 0.48 & 0.01 \\
Lucknow & 38.0 & 20.0 & 0.40 & 0.01 \\
Varanasi & 28.0 & 14.0 & 0.30 & 0.01 \\
\hline
\end{tabular}

which lies in western parts of IG plains may be less than that over Delhi, Varanasi and Lucknow. Thus, with the fixed value of aerosol content, the model is able to predict the visibility over Amritsar better as compared to other stations Delhi, Varanasi and Lucknow, where the aerosols in the real atmosphere may be larger than the fixed value of aerosol content. The number of fog droplets over Delhi may be higher in the real atmosphere as compared to the droplets in the model resulting in lower values of observed visibility over Delhi as compared to the predicted values, although predicted values of relative humidity matches well with observations over Delhi.

Lowest hit rate for both visibility and relative humidity over Lucknow indicates the significance of both the variables, relative humidity and aerosol content, on the prediction of visibility from the model.

The statistical scores for wind speed with threshold of $2 \mathrm{~m} \mathrm{~s}^{-1}$ are given in table 4 . Wind speed is best predicted over Amritsar with highest hit rate of $56 \%$ and bias of 0.58 . However, at other stations, hit rate is found to be $<50 \%$. Less number of correct negatives at all the stations give significant false alarm rate, which result in low values of ETS for both relative humidity and wind speed (tables 3, 4).

The study indicates that predicted values of visibility from NCUM are highly dependent on the
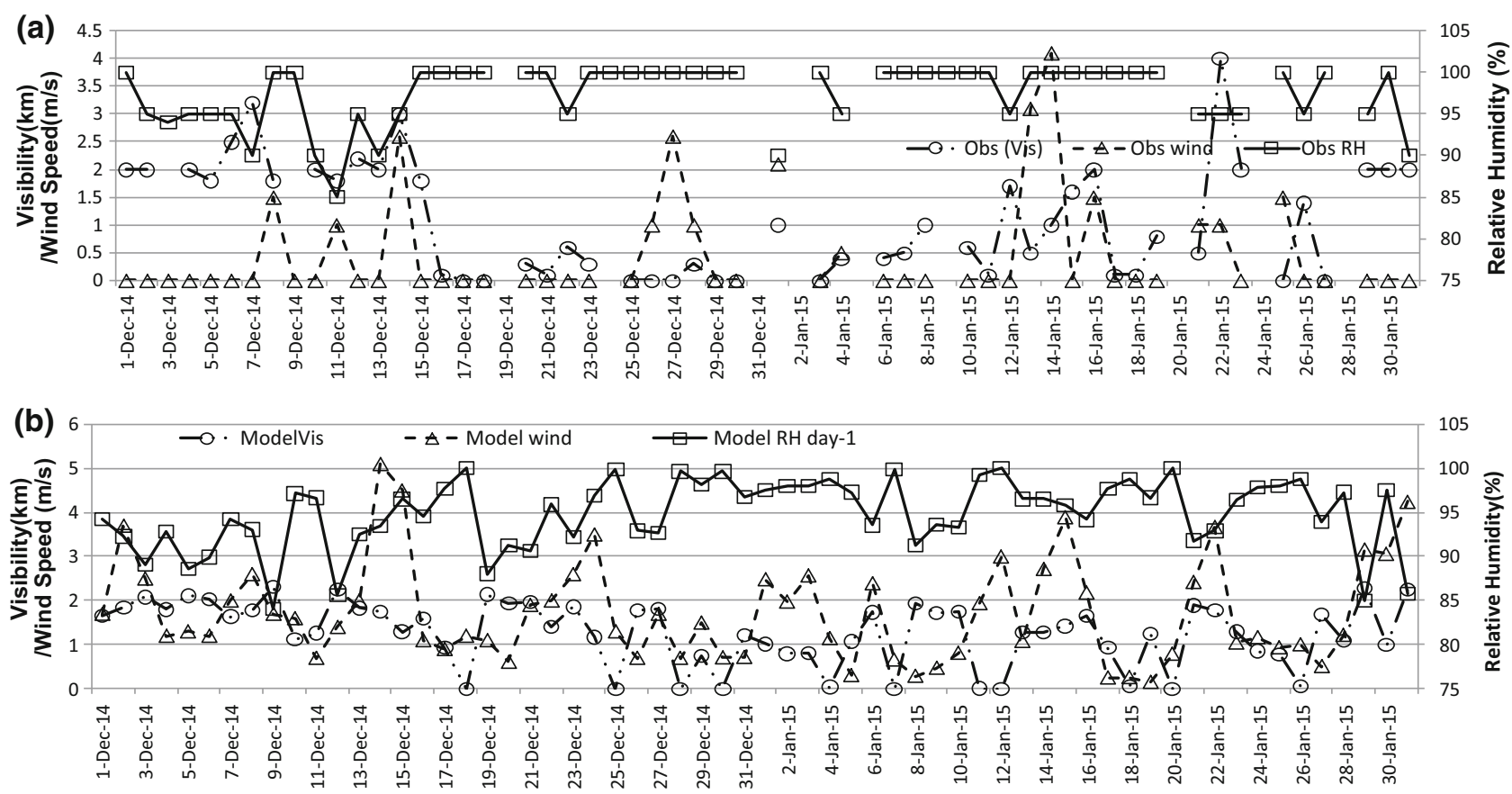

Figure 5. Variation of visibility, relative humidity and wind speed at Amritsar during December 2014-January 2015 (a) observations and (b) day-1 forecast from NCUM. 


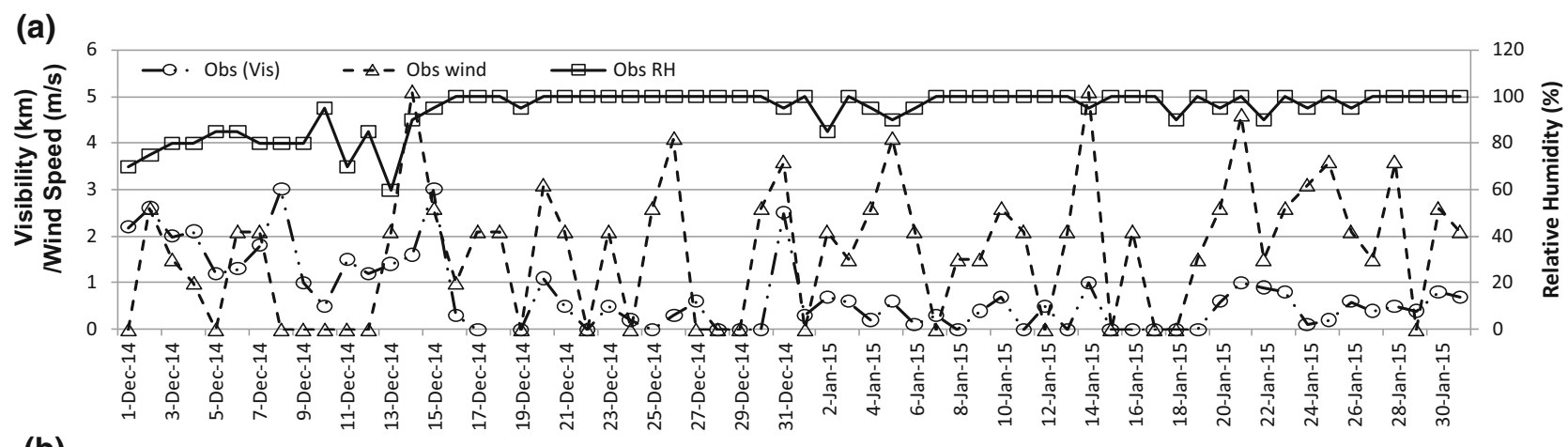

(b)

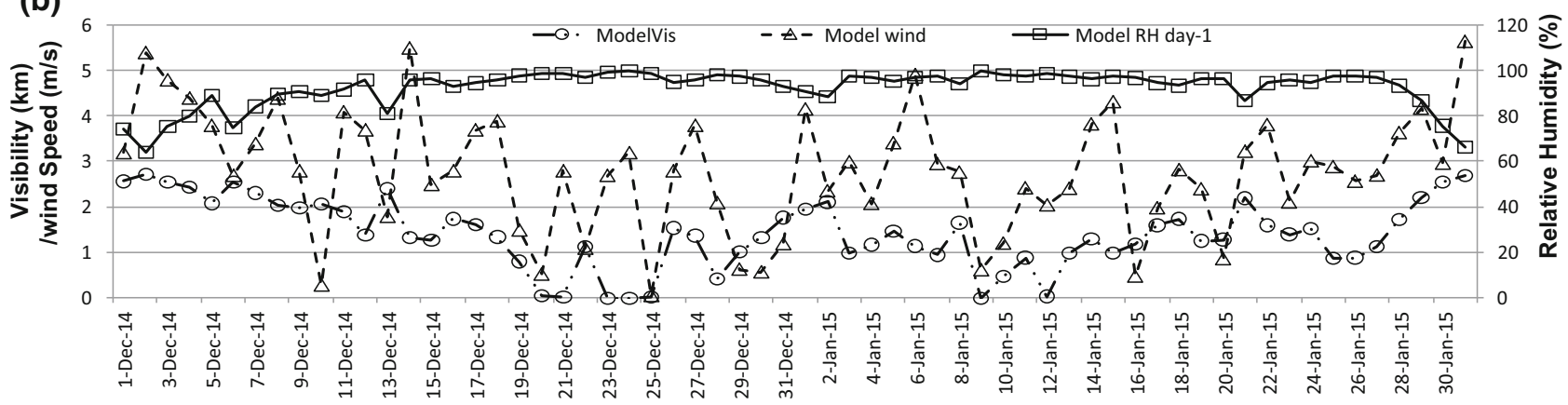

Figure 6. Variation of visibility, relative humidity and wind speed at Delhi during December 2014-January 2015 (a) observations and (b) day-1 forecast from NCUM.
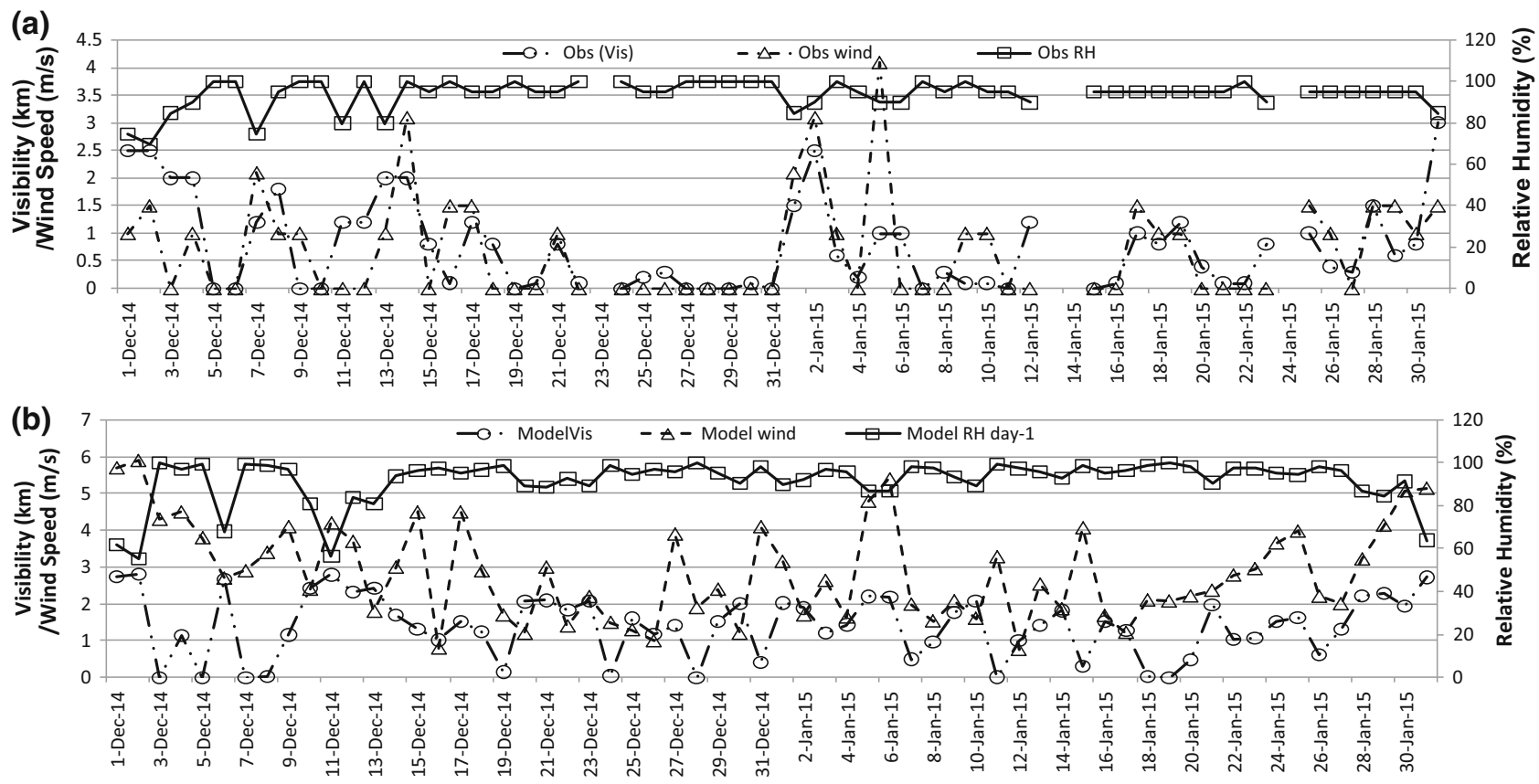

Figure 7. Variation of visibility, relative humidity and wind speed at Lucknow during December 2014-January 2015 (a) observations and (b) day-1 forecast from NCUM.

predicted values of relative humidity. This is due to the fact that a fixed value of aerosol content used for all the locations, limits the formation of number of fog droplets which depends on the value of predicted relative humidity at that location.

\subsection{Diagnostic model for fog prediction}

A simple fog diagnostic model based on surface relative humidity $(\mathrm{RH})$ and wind speed used in this study assumes the presence of fog when 

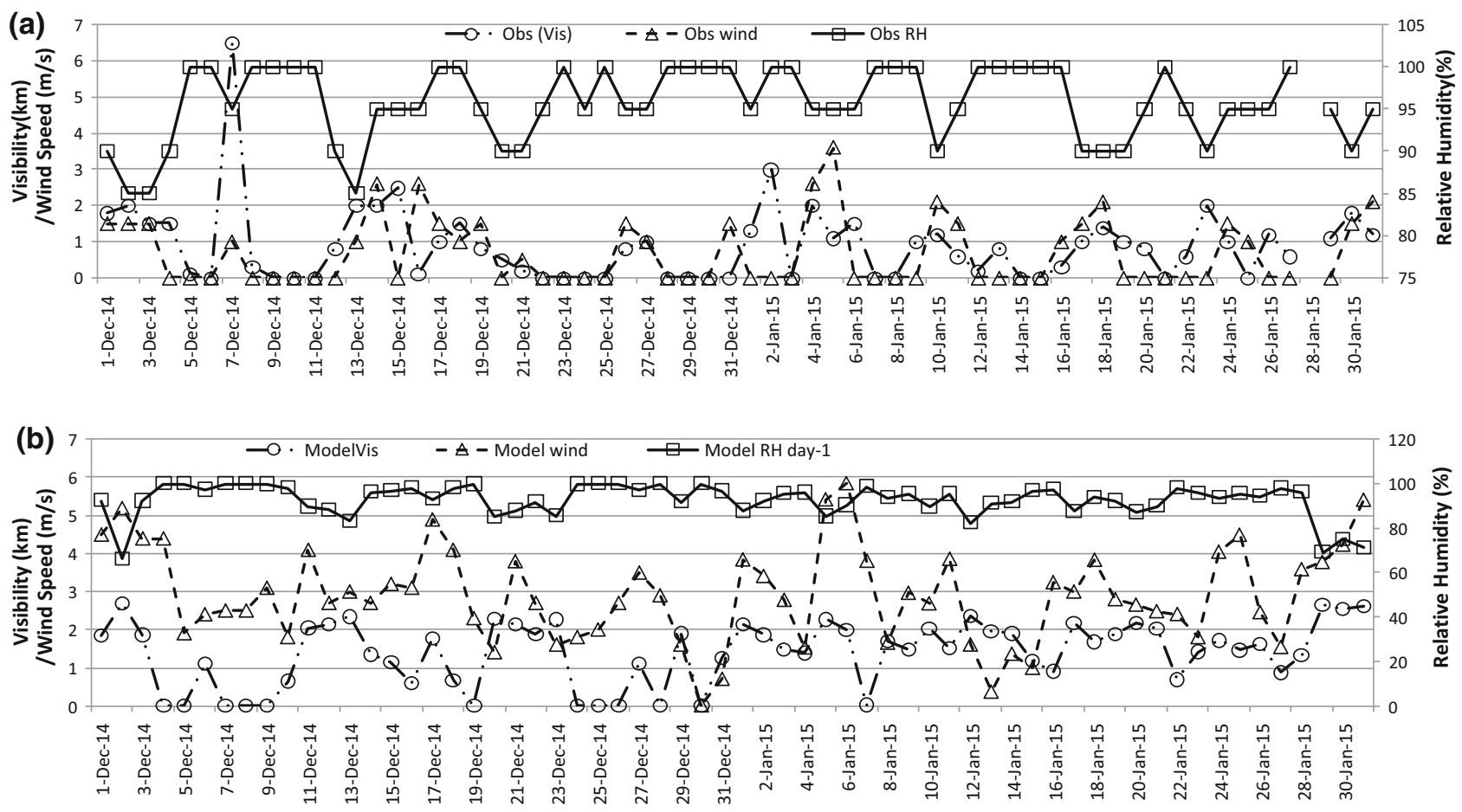

Figure 8. Variation of visibility, relative humidity and wind speed at Varanasi during December 2014-January 2015 (a) observations and (b) day-1 forecast from NCUM.

$2 \mathrm{~m} \mathrm{RH}>90 \%$ and $10 \mathrm{~m}$ wind speed $<2 \mathrm{~m} \mathrm{~s}^{-1}$ (Zhou and Du 2010). The RH-wind rule is applied to both the observed and predicted values of relative humidity and wind speed to detect fog in this study. The analysis of both the observed and model predicted values of visibility, relative humidity and wind speed suggests that the prediction of fog using $\mathrm{RH}$-wind rule with predicted values of relative humidity and wind speed is much sensitive to the values of relative humidity as compared to the values of wind speed. Low visibility values less than $500 \mathrm{~m}$ occur in both observations and model predictions whenever the values of observed and predicted relative humidity are found to be more than $95 \%$. Although observed wind speed is less than $2 \mathrm{~m} \mathrm{~s}^{-1}$ for most of the days when observed visibility is less than $500 \mathrm{~m}$, the predicted values of wind speed are not necessarily $<2 \mathrm{~m} \mathrm{~s}^{-1}$ (figures 5, 6, 7 and 8).

\section{Conclusions}

The performance of NCUM is evaluated for predicting the fog/visibility over parts of north India during winter months. Forecast of visibility from NCUM, largely depends on relative humidity and aerosol content. Day-1 forecast of visibility from NCUM is verified against the INSAT-3D fog image and spatial plot of visibility observations over plains of north India for 28th December 2014, one of the foggy days selected during a fog episode. NCUM is able to predict the spatial extent of fog and drop in visibility corresponding to dense to very dense fog conditions observed on 28th December over plains of north India. Comparison of visibility forecast from NCUM with observations at Amritsar, Delhi, Lucknow and Varanasi during December 2014--Janaury 2015 reveals that NCUM is able to predict the drop in visibility as observed for most of the days. Best agreement between the predicted and observed values of visibility is found at Amritsar. The performance of NCUM is analyzed for predicting relative humidity and wind speed at all the stations. It is found that NCUM is able to predict both the increase in relative humidity beyond its threshold values for most of the days but the decrease in wind speed remains higher than its threshold for majority of days. The diagnostic fog scheme based on the $\mathrm{RH}$ wind rule suggests that the drop in visibility is well predicted by setting the threshold values of $\mathrm{RH}>$ $95 \%$. The visibility predicted with $\mathrm{RH}$-wind rule using the forecast of $\mathrm{RH}$ and wind from NCUM 
is comparable to the visibility predicted using the parameterization scheme of visibility in NCUM.

Present study indicates that NCUM has some skill in predicting the low visibility conditions over different stations. However, the predicted values of visibility are higher compared to the observations. This may be due to the fact that visibility scheme in NCUM depends upon relative humidity and aerosol content. Since the aerosol content is fixed, the values of predicted visibility depend largely on the predicted values of relative humidity. Model is able to predict the relative humidity reasonable well at all the stations but a fixed value of aerosol content is used for all the locations. Improvements in visibility scheme in terms of realistic representation of aerosols can further give better visibility forecast.

\section{Acknowledgements}

Authors would like to acknowledge India Meteorological Department (IMD) for providing the INSAT-3D fog images. They also thank the Head, NCMRWF, for his support in carrying out this work.

\section{References}

Ballard S P, Golding B W and Smith R N B 1991 Mesoscale model experimental forecasts of the Haar of northeast Scotland; Mon. Wea. Rev. 119 2107-2123.

Bang C H, Lee J W and Hong S Y 2008 Predictability experiments of fog and visibility in local airports over Korea using the WRF model; J. Korean Soc. Atmos. Environ. 24 92-101.

Bergot T and Guedalia D 1994 Numerical forecasting of radiation fog. Part I: Numerical model andsensitivity tests; Mon. Wea. Rev. 122 1218-1230.

Best et al. 2011 The Joint UK Land Environment Simulator (JULES), model description - Part 1: Energy and water fluxes; Geosci. Model Dev. 4 677-699.

Brown R and Roach W T 1976 The physics of radiation fog: II - A numerical study; Quart. J. Roy. Meteor. Soc. 102 335-354.

Brown R 1980 A numerical study of radiation fog with an explicit formulation of the microphysics; Quart. J. Roy. Meteor. Soc. 106 781-802.

Brown A R, Beare R J, Edwards J M, Lock A P, Keogh S J, Milton S F and Walters D N 2008 Upgrades to the boundary-layer scheme in the Met Office numerical weather prediction model; Bound.-Layer Meteorol. 128 $117-132$.

Clark P A and Hopwood W P 2001 One-dimensional sitespecific forecasting of radiation fog. Part I: Model formulation and idealized sensitivity studies; Meteorol. Appl. 8 $279-286$.
Clark P A, Harcourt S A, Macpherson B, Mathison C T, Cusack S and Naylor M 2008 Prediction of visibility and aerosol within the operational Met Office Unified Model. I: Model formulation and variational assimilation; Quart. J. Roy. Meteor. Soc. 134 1801-1816.

Clark et al. 2011 The Joint UK Land Environment Simulator (JULES), model description - Part 2: Carbon fluxes and vegetation dynamics; Geosci. Model Dev. 4 701722 .

Davies T, Cullen M J P, Malcolm A J, Mawson M H, Staniforth A, White A A and Wood N 2005 A new dynamical core for the Met Office's global and regional modelling of the atmosphere; Quart. J. Roy. Meteor. Soc. 131 17591782 .

Dey S and Girolama D 2010 A climatology of the aerosol optical and microphysical properties over Indian subcontinent from 9 years (2000-2008) of Multiangle Imaging Spectroradiometer (MISR) data; J. Geophys. Res. 115 D15204.

Duynkerke P G 1999 Turbulence, radiation and fog in Dutch stable boundary layers; Bound.-Layer Meteor. $90447-$ 477.

Edwards J M and Slingo A 1996 Studies with a flexible new radiation code. Part 1: Choosinga configuration for a large-scale model; Quart. J. Roy. Meteor. Soc. 122 689-719.

Fu G, Guo J, Xie S P, Duan Y and Zhang M 2006 Analysis and high-resolution modeling of a dense sea fog event over the Yellow Sea; Atmos. Res. 81 293-303.

Grell G A, Peckham S A, Schmitz R, McKeen S A, Frost G, Skamarock W C and Eder B 2005 Fully coupled online chemistry within the WRF model; Atmos. Environ. 39 6957-6975.

Gregory D and Rowntree P R 1990 A massflux convection scheme with representation of cloud ensemble characteristics and stability dependent closure; Mon. Wea. Rev. 118 1483-1506.

Goswami P and Tyagi A 2007 Advance forecasting of onset, duration and hourly fog intensity over Delhi; Research Report RR CM 0714, Centre for Mathematical Modelling and Computer Simulation, Bangalore, India.

Gultepe I, Pagowski M and Reid J 2007 Using surface data to validate a satellite based fog detection scheme; Wea. Forecast. 22 444-456.

Gupta R K 1987 On the technique of forecasting fog/stratus over the dundigal airfield of Hyderabad; Mausam 38 401-406.

Holtslag A A M, De Bruijn E I F and Pan H L 1990 A high resolution air mass transformation model for short-range weather forecasting; Mon. Wea. Rev. 118 1561-1575.

Jenamani R K and Tyagi A 2011 Monitoring fog at IGI airport and analysis of its runway wise spatio-temporal variations using Meso-RVR network; Mausam 4 491-501.

Lock A P 2001 The numerical representation of entrainment in parametrizations of boundary layer turbulent mixing; Mon. Wea. Rev. 129 1148-1163.

Lock A P, Brown A R, Bush M R, Martin G M and Smith R N B 2000 A new boundary layer mixing scheme, Part 1: Scheme description and single-column model tests; Mon. Wea. Rev. 128 3187-3199.

Mohapatra M and Thulsidas A 1998 Analysis and forecasting of fog over Bangalore airport; Mausam 49 135-142. 
Pagowski M, Gultepe I and King P 2004 Analysis and modeling of an extremely dense fog event in southern Ontario; J. Appl. Meteorol. 43 3-16.

Petersen C and Nielsen N W 2000 Diagnosis of visibility in DMIHIRLAM Scientific Report 00-11; DMI, Copenhagen, Denmark.

Prasad V S 2012 Conversion of NCEP Decoded data to UK MET Office Obstore format; NMRF/OB/01/2012, 33p.

Prasad V S and Indira Rani S 2014 Data Pre-Processing for NCMRWF Unified Model (NCUM): Version 2; NMRF/RR/01/2014, 19p.

Pruppacher H R and Klett J D 1978 Microphysics of clouds and precipitation; D. Reidel Publishing Company, Dordrecht, Netherlands.

Rajagopal E N, Iyengar G R, George J P, Das Gupta M, Mohandas S, Siddharth R, Gupta A, Chourasia M, Prasad V S, Aditi Sharma K and Ashish A 2012 Implementation of Unified Model based Analysis-Forecast System at NCMRWF; NMRF/TR/2/2012, 45p.

Rao G V and Sullivan J O 2003 A review of some recent radiation fog prediction studies and the results of integrating a simple numerical model to predict radiation fog over Brunei; Pure Appl. Geophys. 160 239-250.

Roybhowmik S K, Sud A M and Singh C 2004 Forecasting fog over Delhi - An objective method; Mausam 55 313-322.

Smirnova T G, Benjamin S G and Brown J M 2000 Case study verification of RUC/MAPS fog and visibility forecasts; In: $9^{\text {th }}$ Conference on Aviation, Range, and Aerospace Meteorology, Orlando, FL, American Meteorological Society, Boston.
Swagat P and Mohan M 2014 Multirule based diagnostic approach for fog prediction using WRF modeling tool; Adv. Meteorol. 2014 Article ID 456065.

Van der Velde I R, Steeneveld G J, Wichers Schreur B G J and Holtslag A A M 2010 Modeling and forecasting the onset and duration of severe radiation fog under frost conditions; Mon. Wea. Rev. 138 4237-4253.

Wilson D R and Ballard S P 1999 A microphysically based precipitation scheme for the UK meteorological office unified model; Quart. J. Roy. Meteor. Soc. 125 1607-1636.

Wilson D R, Bushell A C, Kerr-Munslow A M, Price J D and Morcrette C J 2008a PC2: A prognostic cloud fraction and condensation scheme. 1: Scheme description; Quart. J. Roy. Meteor. Soc. 134 2093-2107.

Wilson D R, Bushell A C, Kerr-Munslow A M, Price J D, Morcrette C J and Bodas-Salcedo A 2008b PC2: A prognostic cloud fraction and condensation scheme: Climate model simulations; Quart. J. Roy. Meteor. Soc. 1342109 2125 .

Zdunkowski W and Nielsen B 1969 A preliminary prediction analysis of radiation fog; Pure Appl. Geophys. 19 45-66.

Zhou B, Du J, Ferrier B S, McQueen J and DiMego G 2007 Numerical forecast of fog - central solutions; In: Proceedings of the $2^{\text {nd }}$ Conference on Weather Analysis and Forecasting and $18^{\text {th }}$ Conference on Numerical Weather Prediction, American Meteorological Society, Park City, Utah, USA, http://ams.confex.com/ams/ pdfpapers/123669.pdf.

Zhou B and Du J 2010 Fog prediction from a multimodel mesoscale ensemble prediction system; Wea. Forecast. 25(1) 303-322. 